\title{
ESPACIO E INTERTEXTUALIDAD EN EL DE DEO SOCRATIS DE APULEYO $^{1}$
}

\author{
Roxana Nenadic \\ Universidad de Buenos Aires, Argentina \\ rnenadic@gmail.com
}

\section{Resumen:}

En De deo Socratis, Apuleyo introduce a su auditorio en el mundo de la demonología medioplatónica. La conferencia se articula, entre otros elementos, con variadas referencias espaciales e intertextuales. Las nociones espaciales, familiares al auditorio, posibilitan el avance y la presentación de ejemplos y argumentos, y son formuladas acudiendo a textos de un capital cultural también compartido. La combinación de ambas variables, espacialidad e intertextualidad, resulta eficaz a los fines del discurso en la medida en que explota elementos conocidos por el orador y su público.

Palabras Clave: Apuleyo, De deo Socratis, Espacio, Intertextualidad.

\section{Abstract:}

In De Deo Socratis Apuleius introduces his audience to the world of Medioplatonic demonology. Among other elements, the conference is articulated with varied spatial and intertextual references. The spatial notions, familiar to the audience, enable the display and development of examples and arguments, and are formulated by reference to texts of a shared cultural capital. The combination of both variables, spatiality and intertextuality, is effective for the purposes of discourse to the extent that it exploits elements known by the speaker and his audience.

KEYWORDs: Apuleyo, Deo Socratis, Space, Intertextuality.

En la conferencia conocida como De deo Socratis, Apuleyo introduce a su auditorio en el mundo de la demonología medioplatónica. Ciertamente, su disertación representa un diálogo intertextual e intercultural en más de un sentido. Para empezar, las circunstancias del discurso plantean un encuentro entre tradición filosófica y tradición retórica. Por un lado, las continuas referencias de Apuleyo a una nutrida audiencia, el empleo del estilo medio ${ }^{2}$-fluido y con un ornato basado en la sonoridad y en la fácil comprensión ${ }^{3}$ y las semejanzas compositivas entre este texto y los fragmentos de Florida (una antología de sus discursos epidícticos), nos remiten a la práctica profesionalizada de la retórica del siglo II d.C. Por otro, su tema se corresponde muy especialmente con el interés propio de la época en la divulgación filosófica, mezcla de diatriba y de misticismo, la que, vale recordar, en el caso de Apuleyo, se configuró como una verdadera carta de presentación de su figura autoral. ${ }^{4}$ En este aspecto, se ha señalado en numerosas ocasiones el esfuerzo de nuestro autor por legitimar el papel de la retórica frente a la filosofía, acallando las connotaciones negativas y las suspicacias generadas en torno de la palabra persuasiva y subrayando su aporte fundamental en la comunicación de contenidos considerados valiosos para la comunidad. ${ }^{5}$

Además, De deo Socratis no solo se nutre de los diálogos platónicos en su versión demidiata de los primeros siglos d.C., sino que es la contrapartida latina de otros textos griegos que abordaron la misma temática, como el De genio Socratis de Plutarco o las Dialexeis 8 y 9 de su contemporáneo Máximo de Tiro. ${ }^{6}$ En este marco, Apuleyo compone con un criterio propio sobre este material compartido, e incluso intenta asimilar al sistema demonológico los dioses domésticos de la religión romana -genii, lemures, lares, laruae y manes. ${ }^{7}$ 
Por último en esta lista, mencionemos el hecho de que el madaurense articula su exposición dialógicamente, valiéndose de la alusión, la paráfrasis y la cita tanto del corpus platónico y homérico cuanto de autores latinos -Virgilio, Ennio, Plauto, Cicerón, Lucrecio, Séneca, entre otros-. Su discurso gana en estilización y autoridad sirviéndose del continuum del campo intelectual imperial.

Es fácil advertir, entonces, que esta conferencia surge de y en la convergencia de múltiples factores, y por ello es lícito indagar en los mecanismos puestos en juego para encaminar elementos no del todo afines hacia un cometido que es espectacular y didáctico a la vez. Nos proponemos aquí examinar el funcionamiento de dos elementos que, a nuestro entender, aportan a la cohesión de la factura discursiva. Las nociones espaciales, familiares al auditorio, posibilitan el avance y la presentación de ejemplos y argumentos, y son formuladas acudiendo a textos de un capital cultural también compartido. La combinación de ambas variables, espacialidad e intertextualidad, resulta eficaz a los fines del discurso en la medida en que explota elementos conocidos por el emisor y sus destinatarios.

Más allá de las inconsistencias detectables en las explicaciones del madaurense -como, por ejemplo, que Minerva figure como ejemplo de diosa, de daemon y de alegoría de la sabiduría-, ${ }^{8}$ la estructura de De deo Socratis es clara y evidencia desde el inicio que su búsqueda central es la del vínculo con sus oyentes. En efecto, podemos distinguir una primera parte (\$115-156), más teórica, que desarrolla la jerarquía tripartita de los seres superiores -dioses, hombres y daemones-, sus cualidades y características, seguida de una segunda y última (\$157-178) enfocada en el caso concreto del daemon de Sócrates, cuyo ejemplo de vida invita a seguir. Esta articulación permite resaltar el contenido parenético por sobre el especulativo, a diferencia de la de su coetáneo Máximo de Tiro, ${ }^{9}$ que va de lo particular -el daemon socrático- hacia lo general -la demonología. Este interés en el posible impacto causado en el auditorio se manifiesta, además, en la preferencia de Apuleyo por ciertos patrones explicativos, considerados, sin duda, de captación inmediata. Veamos ejemplos extraídos de la primera parte de la conferencia:

Plato omnem naturam rerum, quod eius ad animalia praecipua pertineat, trifariam diuisit censuitque esse summos deos. Summum, medium et infimum fac intellegas non modo loci disclusione uerum etiam naturae dignitate, quae et ipsa neque uno neque gemino modo sed pluribus cernitur. Ordiri tamen manifestius fuit a loci dispositione. Nam proinde ut maiestas postulabat, diis inmortalibus caelum dicauit, quos quidem deos caelites partim uisu usurpamus, alios intellectu uestigamus. Ac uisu quidem cernimus:

... uos, o clarissima mundi

lumina, labentem caelo quae ducitis annum;

nec modo ista praecipua: diei opificem et lunamque, solis aemulam [...] (\$115-116)

Platón dividió toda la naturaleza, en lo concerniente a sus principales seres animados, en tres partes, y consideró que existen dioses superiores. El hecho de que hay seres superiores, intermedios e inferiores debes entenderlo no solo por la separación de su ubicación, sino también por el mérito de su naturaleza, que se distingue en sí misma, no de uno o dos modos, sino de muchos. Sin embargo, comenzó, como más patente, por la distribución de su ubicación. En efecto, conforme lo exigía su majestad, consagró el cielo a los dioses inmortales, divinidades celestiales a las que captamos en parte con la vista y a otras descubrimos con la inteligencia. Ciertamente con la vista las distinguimos

...a ustedes, clarísimas luces del mundo

que conducen en el cielo la marcha del año;

y no solo a estas principales, el artífice del día y la luna, rival del sol $[. . .]^{10}$

Se trata del principio del texto conservado, que explicita en sí todo un programa temático y compositivo. Obviamente, la división de los seres animados, la asignación de lugares distintos a cada uno (cielo, aire, tierra) y la correspondencia entre dichos lugares, los elementos correspondientes (fuego, aire, agua y tierra) y sus cualidades principales, no son en absoluto contribuciones apuleyanas, sino que pueden rastrearse, por solo citar las fuentes mencionadas con mayor frecuencia por la crítica, en el Epinomis, en el Timeo (39e), en el Simposio $\left(202 \mathrm{e}-203^{\mathrm{a}}\right.$ ) y en el De natura deorum de Cicerón (II, 15, 42) ${ }^{11}$. Lo que nos interesa destacar aquí es, justamente, lo que nuestro autor buscó resaltar mediante sus giros estilísticos habituales. Por un lado, la apelación a los sentidos, de manera literal o figurada, como medio para acceder al conocimiento, formulada en 
una estructura de homoitéleuton (partim uisu usurpamus, alios intellectu uestigamus), por el otro, el hecho de que la división de los seres se aprecia más claramente en su distribución espacial. Esto no solo es nombrado dos veces en el pasaje que acabamos de citar, sino que también es formulado con el hápax disclusio (loci disclusione, loci dispositione). Sigue la cita de Geórgicas 5-6 sobre los astros, los primeros de una lista de dioses que será ampliada profusamente a continuación recurriendo a la intertextualidad: con el libro $\mathrm{V}$ de De rerum natura en una écfrasis sobre las fases de la luna:

[...] lunamque, solis aemulam, noctis decus, seu corniculata seu diuidua seu protumida seu plena sit, uaria ignium face, quanto longius facessat a sole, tanto largius conlustrata, pari incremento itineris et luminis, mensem suis auctibus ac dehinc paribus dispendiis aestimans; siue illa proprio sed perpeti candore pollens, ut Chaldaei arbitrantur, parte luminis conpos, parte altera cassa fulgoris, pro circumuersione oris discoloris multiiuga speciem sui uariat, seu tota proprii candoris expers, alienae lucis indigua, denso corpore sed leui ceu quodam speculo radios solis obstipi uel aduersi usurpat et, ut uerbis utar Lucreti,

notham iactat de corpore lucem $[. .].(\$ 117-118)$

[...] y la luna, rival del sol, adorno de la noche, ya sea creciente, ya a la mitad, ya inflada, ya llena, con variado aspecto en su luminosidad, cuanto más lejos se distancia del sol, tanto más extensamente iluminada, con un incremento equivalente de su camino y de su luz, calculando el mes son sus aumentos y haciéndolo a continuación con iguales pérdidas. Es capaz de hacer esto ya sea por su fulgor propio y eterno, como piensan los caldeos, compuesta en una parte de luz, en otra carente de resplandor, en virtud de variar con diversidad su aspecto conforme gira su forma de distintos colores, ya sea que, falta enteramente de brillo propio, necesitada de una luz ajena, de cuerpo denso pero ligero como una suerte de espejo toma los rayos del sol oblicuo o de frente y, para servirme de Lucrecio,

arroja de su cuerpo una luz bastarda [...]

La constitutio textus de este pasaje ha sido en sí un problema para la crítica, que acuerda en señalar que la mayor dificultad consiste en interpretar la variedad de perspectivas y fuentes amalgamadas. ${ }^{12}$ Esto nos habla con elocuencia del mecanismo compositivo intertextual del madaurense, quien realiza aquí una cita más bien conceptual de Lucrecio V, 576 (siue suam proprio iactat de corpore lucem). Casi enseguida, es rememorado Cicerón (N. D. II, 51) en su definición de las estrellas errantes: quinque stellas, quae uulgo uagae ab inperitis nuncupantur, "cinco estrellas, que comúnmente son llamadas errantes por los ignorantes" (\$119). ${ }^{13}$

Sobre el cierre de esta sección encontramos la cita de Eneida III, 516, empleada para mencionar estrellas, y las notables imágenes de Ennio (Annales I, 27 y VII, 240):

In eodem uisibilium deorum numero cetera quoque sidera, qui cum Platone sentis, locato:

Arcturum $\mathrm{p}<$ luuiasque $>\mathrm{Hy}<$ adas $>$ g $<$ eminosque $>\mathrm{T}<$ riones $>$

aliosque itidem radiantis deos, quibus caeli chorum comptum et coronatum suda tempestate uisimus, pictis noctibus seuera gratia, toruo decore, suspicientes in hoc perfectissimo mundi, ut ait Ennius, clipeo miris fulgoribus uariata caelamina.

Est aliud deorum genus, quod natura uisibus nostris denegauit, nec non tamen intellectu eos rimabundi contemplamur, acie mentis acrius contemplantes. Quorum in numero sunt illi duodecim [numero] situ nominum in duo uersus ab Ennio coartati:

Iuno, Vesta, Minerua, Ceres, Diana, Venus, Mars,

Mercurius, Iouis, Neptunus, Vulcanus, Apollo. (\$120-121)

En la misma lista de dioses visibles, quienes piensan con Platón ubiquen también los restantes astros:

Arturo, las lluviosas Híadas y las dos Osas,

e igualmente a las otras divinidades radiantes, por quienes vemos, con tiempo despejado, adornado y coronado el coro del cielo, pintadas las noches con elegancia austera, con hermosura amenazante, cuando alzamos la vista en este perfectísimo, como dice Ennio, escudo del mundo y contemplamos sus grabados llenos de matices de asombrosos fulgores.

Hay otra clase de dioses, que la naturaleza negó a nuestros ojos, y que sin embargo contemplamos con la inteligencia al buscarlos con afán, contemplándolos con la agudeza de la mente. En su número se encuentran aquellos doce apretados por Ennio en dos versos:

Juno, Vesta, Minerva, Ceres, Diana, Venus, Marte,

Mercurio, Júpiter, Neptuno, Vulcano, Apolo.

Todos estos textos se ofrecen como ejemplos del mundo conocido que serán reconsiderados a partir de las explicaciones del discurso. Lo notable del contenido que hemos reseñado es la complementariedad entre espacio, literatura y percepción. En primer lugar, Apuleyo recurre al razonamiento que considera más 
evidente, más inmediato, más naturalmente lógico: los seres perfectos habitan el lugar más alto. En otras palabras, emplea el cielo no tanto como un lugar estrictamente físico sino más bien como un espacio en los términos de de Certeau, esto es, como un lugar atravesado por las prácticas y las variables culturales. ${ }^{14}$ En este caso, "cielo" vale por "lugar de jerarquía máxima", gracias a determinantes como su altura y accesibilidad. Además, Apuleyo invita a releer, a volver a mirar ese espacio con los ojos de la literatura, que funciona aquí como garante de lo dicho y como estímulo para la percepción. Cabe rescatar en este punto el componente pragmático y semiótico de toda conferencia: podríamos imaginar al orador señalando el cielo, citando meticulosas descripciones de lo que en él ocurre, guiando la imaginación de su auditorio. Recordemos el papel central de la fantasía en la enseñanza y la práctica oratorias, aspecto trabajado por autores como Webb respecto de la écfrasis. ${ }^{15}$ La estudiosa resalta que tanto en los tratados griegos del período imperial como en la obra de Quintiliano (este último refiriéndose a la euidentia), la construcción de este ejercicio descriptivo se basa en el detalle y su éxito depende de su capacidad de impresionar al público. Esto último era entendido como la posibilidad efectiva de visualización de lo verbalizado. Webb apunta que la concepción teórica subyacente es la correlación entre lenguaje, fantasía y mirada. La fantasía es compartida por emisor y receptor, y las imágenes por ella evocadas ya están de alguna manera presentes en la memoria de ambos, en la medida en que parten de un capital cultural común - una galería finita de lugares comunes transmitidos por la paideía.

Aunque nuestras citas no conforman estrictamente una écfrasis, podemos postular que la acumulación de heterogeneidades discursivas de la conferencia actúa de manera análoga en la producción de impresiones y efectos de sentido. ${ }^{16}$ Ciertamente, la selección de autores apuleyana forma parte del canon científico, filosófico y literario latino e incorpora múltiples representaciones (los dioses, las estrellas, la luna, etc.). Por ello funciona como un equivalente de la galería de imágenes que articula un proceso ecfrástico. Interpelado por este marco de visualizaciones y nociones confiables, el oyente ideal se deja guiar a través de las novedades que el orador propone dentro de un horizonte de expectativas compartido. A pesar de la universalidad del problema a dilucidar en la conferencia y del origen griego de la doctrina a desarrollar, uno no puede dejar de notar el romanocentrismo de la serie: los ejes espaciales jerarquizados, los intertextos latinos y la gradación que reserva el último lugar al autor más antiguo, Ennio, apuntan a una formación ideológica romana. ${ }^{17}$ Para decirlo de otro modo, el discurso será fiable y sus exposiciones serán verosímiles no solo porque recurran a categorías de un trasfondo cultural específico, sino también porque insinúan que, de alguna manera, Roma era ya, desde sus primeras letras, poseedora de esa sabiduría atribuida a Grecia.

Como hemos adelantado, la apelación a las categorías espaciales continuará a lo largo del discurso. Por ejemplo, más adelante, tras explayarse sobre la inefabilidad del dios superior, Apuleyo cierra la sección en estos términos:

[...] ac iam rebus mediocritatem meam [in] longe superantibus receptui canam tandemque orationem de caelo in terram deuocabo. In qua praecipuum animal homines sumus [...] (\$125)

[...] tocaré a retirada en temas que superan largamente mi mediocridad y, finalmente, haré bajar mi discurso del cielo a la tierra. En esta los hombres somos los seres superiores [...]

En este caso, nos encontramos con la espacialidad expresada con índices de dirección (de caelo in terram). La lógica espacial instalada en el discurso permite adelantar el contraste de las situaciones relativas de dioses y de hombres. El solo hecho de que los hombres habiten el lugar de abajo, la tierra, habla de sus imperfecciones y sufrimientos. Esta vez, pareciera que la propia experiencia individual basta para refrendar lo expuesto, ya que no se proponen miradas al territorio en sí sino a la vida de los mortales, que Apuleyo sintetiza así:

Igitur homines ratione gaudentes, oratione pollentes, inmortalibus animis, moribundis membris, leuibus et anxiis mentibus, brutis et obnoxiis corporibus, dissimillimis moribus, similibus erroribus, peruicaci audacia, pertinaci spe, casso labore, fortuna caduca, singillatim mortales, cunctim tamen uniuerso genere perpetui, uicissim sufficienda prole mutabiles, uolucri tempore, tarda sapientia, cita morte, querula uita, terras incolunt. (\$126)

Por tanto, los hombres, que gozan de la razón, poderosos por el discurso, de alma inmortal, de miembros perecederos, de mentes ligeras y cuidadosas, de cuerpos pesados y torpes, de costumbres muy distintas entre sí, de errores semejantes, de 
audacia obstinada, de esperanza perseverante, de esfuerzos insustanciales, de suerte transitoria, mortales tomados de a uno, perpetuos considerados en su conjunto, renovados considerando su descendencia, de vida efímera, de sabiduría tardía, de rápida muerte, de vida quejosa, habitan la tierra.

Casi como el lugar antropológico de Augè ${ }^{18}$ en el sentido de un territorio dador de identidad y atravesado por puntos de contacto y de relación con otros, la tierra encierra a los hombres y los preconfigura. La sintaxis básica de la frase, homines... terras incolunt, se ve acrecentada por los atributos de los mortales, encerrados simbólicamente entre sujeto y verbo. Si se es hombre, se vive en la tierra y se es de ese modo. Los paralelismos y las aliteraciones no solo enfatizan los rasgos, sino añaden patetismo a las diferencias entre hombres y dioses. Esto es aprovechado en los parágrafos siguientes que, también desde una perspectiva espacial, se preguntan sobre la necesidad de la existencia de estos seres intermedios e intermediarios que son los daemones:

Habetis interim bina animalia: deos ab hominibus plurimum differentis loci sublimitate, uitae perpetuitate, naturae perfectione, nullo inter se propinquo communicatu, cum et habitacula summa ab infimis tanta intercapedo fastigii dispescat et uiuacitas illic aeterna et indefecta sit, hic caduca et subsiciua, et ingenia illa ad beatitudinem sublimata sint, haec ad miserias infimata. Quid igitur? Nullone conexu natura se uinxit, sed in diuinam et humanam partem partitam se et interruptam ac ueluti debilem passa est? (\$127-128)

Tienen ustedes, entretanto, dos clases de seres animados: los dioses, muy diferentes de los hombres, por la sublimidad de su morada, por la eternidad de su vida, por la perfección de su naturaleza, y por no haber entre ellos ninguna participación al alcance, ya que separa una tan inmensa distancia sus sublimes moradas de estas ínfimas regiones y allí el vigor de vida es eterno e inagotable y aquí caduco y perecedero, y aquellos espíritus se hallan elevados a la beatitud y los humanos degradados a las miserias. ¿Qué, entonces? ¿La naturaleza no se ata a sí misma con ningún nexo, sino que ha permitido ser dividida e interrumpida en una parte divina y otra humana y quedar como debilitada?

Las referencias espaciales simplifican la dificultad teórica que supone dilucidar la realidad de estos seres, que casi nadie ha visto y de los que, a diferencia de los dioses, casi nadie habla. Por un lado, la brecha entre hombres y dioses se formula mediante nociones de altura y profundidad extremas (loci sublimitate, habitacula summa, ab infimis, sublimata sint, infimata); por el otro, la falta de vida en ese sitio entre el cielo y la tierra es asociada con una ruptura inconcebible del espacio (intercapedo, interruptam). Frente a cualquier otro procedimiento lógico, el plano de la vivencia espacial se impone: si no hay separación visible entre el lugar llamado "cielo" y el lugar llamado "tierra" tampoco debería haber interrupción de vida en el lugar intermedio. La crítica llama la atención sobre este enfoque peculiar de Apuleyo, quien insiste más en este aspecto territorial que el resto de los autores, que hacen hincapié, más bien, en las diferencias de naturaleza de los diversos seres. ${ }^{19}$

Apenas más adelante en este mismo pasaje, la distancia entre hombres y dioses es planteada con una analogía arquitectónica:

Quod quidem mirari super diis inmortalibus nequaquam congruerit, cum alioquin et inter homines, qui fortunae munere opulenti elatus et usque ad regni nutabilem suggestum et pendulum tribunal euectus est, raro aditu sit, longe remotis arbitris in quibusdam dignitatis suae penetralibus degens. (\$128-129)

En verdad, respecto de los dioses inmortales, de nigún modo sería adecuado asombrarse de esto, cuando, por otra parte, entre los hombres quien se encuentra elevado por un opulento favor de la fortuna y ha sido llevado a la altura inestable y al trono vacilante de un reino es de raro acceso, viviendo, alejados los testigos, como en un santuario de su propia reputación.

El hombre poderoso se encuentra en los penetralia y es de raro aditu. Introducir esta semejanza con los dioses sugiere, nuevamente, la posibilidad de que haya quienes, como intermediarios, recorran los pasajes hasta estas zonas ínteriores y jerarquizadas. Además de validar la comunicación entre los seres con un elemento de fuerte raigambre ideológica como son las relaciones político-religiosas, el uso de comparaciones edilicias representa otro aspecto de la correlación que venimos mencionando entre cualidades, asignaciones espaciales e ideología. Autores como Mc Intosh observan que la arquitectura, a través de la delimitación y distribución de lugares de ocultamiento y visibilidad en las construcciones que diseña, colabora en el proceso de establecimiento de las relaciones interpersonales, de las posiciones relativas de los individuos y de sus identidades sociales. ${ }^{20}$ En este sentido, podemos pensar que el discurso apela a una percepción del espacio 
mediatizada culturalmente por partida doble ya que las nociones de ubicación que veníamos observando hasta ahora se aplican esta vez en el interior de un lugar regulado por indicaciones espaciales propias.

Luego de algunos párrafos referidos a los juramentos, que amplifican, con citas de la Eneida (IX, 300 y X, 773), la idea de la intervención en ellos de una figura mediadora que los hace llegar a los dioses, avanzamos hasta la presentación de los daemones:

Ceterum sunt quaedam diuinae mediae potestates inter summum aethera et infimas terras in isto intersitae aëris spatio, per quas et desideria nostra et merita ad eos commeant. (\$132)

Por lo demás, existen ciertos poderes divinos intermedios ubicados en el espacio del aire entre lo más alto del éter y las bajísimas tierras, a través de los cuales circulan hasta los dioses tanto nuestros deseos como nuestros méritos.

Más adelante tendremos la definición completa de estos seres como animados, racionales, pasionales, aéreos y eternos (\$148), pero en este punto, Apuleyo insiste una y otra vez en una caracterización apoyada en categorías espaciales. El daemon ocupa un espacio específico (in isto intersitae aeris spatio) que, a su vez, lo describe como uector, como "transportador" (\$133). Está presentado con índices de movilidad y estatismo al mismo tiempo, puesto que las referencias a su circulación como mensajero se concretan con verbos compuestos de eo (commeant $\$ 132$, obeunt $\$ 136$ ), mientras que sus funciones específicas se mencionan como prouinciae (Eorum quippe de numero praediti curant singuli [eorum], proinde ut est cuique tributa prouincia, "Cada uno de estos, en efecto, tiene a su cargo el cuidado de aspectos especiales, según el campo -prouinciaasignado a cada cual”, \$133-134). Todas estas indicaciones conforman un marco de lectura e interpretación de la larga serie de ejemplos que llenarán el discurso, desde la paráfrasis de Simposio 202b en que se menciona el papel de los daemones en los presagios, hasta los exempla históricos de Aníbal, Flaminio, Ato Navio, Tarquinio Prisco y Servio Tulio. Retomando nuestras observaciones acerca de la imaginación en la recepción de un discurso, aquí el camino pareciera ser el inverso: esta vez, la mención de la asistencia física de los daemones ilumina el acervo literario. Los exempla se vuelven, literalmente, escenarios para el accionar demónico.

Las elucubraciones espaciales también facilitan la discusión sobre la consistencia de sus cuerpos. Sinteticemos solo algunas frases del extenso pasaje:

Debemos, por lo tanto, imaginar una composición de una naturaleza intermedia (media natura) en razón de su ubicación media (pro loci medietate) $[\ldots](\$ 140)$

No muy lejos de esta sutilidad corporal vemos formadas a las nubes [...] Pues bien, suspensas y móviles (pendulae et mobiles) son dirigidas por los vientos de acá para allá dirigidas, a la manera de navíos (uice nauium) en el océano del aire, cambiando muy poquito según su proximidad o lejanía (proximitate et longinquitate) (\$142)

Los daemones tienen una conformación semejante a la de las nubes, no tanto por su consistencia como por su capacidad de mantenerse en su hábitat y circular en él. Nosotros nos detenemos aquí. La conferencia continuará con el meollo teórico de la exposición: la sistematización de los tipos de daemones y el ensayo de una interpretatio romana.

Esperamos haber ilustrado la valencia estructurante y cognitiva de los parámetros espaciales en algunos pasajes de De deo Socratis significativos por su posición medular o transicional. Un espacio, en una cultura dada, rara vez es solamente un sitio donde acomodar cosas, sino que, muy por el contrario, los espacios se configuran a partir de su encuentro con otros elementos de la serie cultural. Es así como se relacionan espacios y prácticas sociales, espacios y axiología, espacios e identidades. Los pasajes que hemos considerado nos mostraron la funcionalidad del espacio en la articulación de esta conferencia en distintos niveles. A nivel de la estructura misma del discurso, hemos observado hasta qué punto la progresión y el encadenamiento en el desarrollo conceptual provienen de la aplicación de una mirada espacializada: de arriba hacia abajo, del cielo a la tierra, y de allí al lugar medio. Por otro lado, hemos notado la contribución de las nociones espaciales a la argumentación. El énfasis en la pertenencia a un lugar determinado tiene como consecuencia la asignación de ciertos rasgos y no otros, en la jerarquía tripartita de los seres superiores. Además, la confiabilidad de estos parámetros espaciales se vislumbra en el hecho de que aparecen destacados por recursos estilísticos 
diversos. En este contexto, la literatura, representada en la estilización del discurso y en las variadas formas de la intertextualidad, se suma a la factura de De deo Socratis para refrendar los contenidos y para ocupar, ella misma, un lugar en la observación del mundo visible e invisible. En el esquema propuesto por Apuleyo, los textos literarios funcionan como epígrafes interpretativos de los lugares que percibimos, ya con los sentidos, ya con nuestro intelecto. Pareciera que en el mundo -en el cielo, en la tierra- está escrito lo que afirma un texto, o que el mundo mismo es la comprobación más fehaciente del texto.

\section{Notas}

1 Una primera versión de este trabajo, bajo el título "Espacialidad, intertextualidad y argumentación en el De deo Socratis de Apuleyo," fue presentada en las VIII Jornadas de Estudios Clásicos y Medievales "Amor y metamorfosis de la Antigüedad a la Edad Media”, Centro de Estudios Latinos - Instituto de Investigaciones en Humanidades y Ciencias Sociales, UNLP - Conicet, 18 al 20 de septiembre de 2017.

2 Medius hic modus et tralationibus crebrior et figuris erit iucundior, egressionibus amoenus, compositione aptus, sententiis dulcis, lenior tamquam amnis et lucidus quidem sed uirentibus utrimque ripis inumbratus (El estilo medio será de metáforas más frecuentes y más agradable por el uso de figuras, encantador por las disgresiones, armonioso en su redacción, dulce en los conceptos y muy suave, como un río, ciertamente luminoso pero envuelto en sombras a uno y otro lado de sus verdeantes orillas), Quint. Inst. XII, 10, 60.

3 Sobre este aspecto de la prosa apuleyana, cfr. Facchini Tosi, C. Euphonia. Studidifonostilistica (Virgilio, Orazio, Apuleio), Bologna, Pàtron Editore, 2000, 113-189

4 Sobre la construcción del orador como filósofo en este texto en particular, cfr. Hijmans, B. L., "Apuleius, Philosophus Platonicus", $A N R W$ II.36.1, 1987, 425-427.

5 Cfr. los conceptos de O'Brien, M., “Apuleius and the Concept of a Philosophical Rhetoric”, Hermathena 151, 1991, 39-50. Un estudio pormenorizado de la construcción de la figura de Apuleyo como vocero de la Filosofía puede verse en Fletcher, R. Apuleius' Platonism: the Impersonation of Philosophy, Cambridge, Cambridge University Press, 2014.

6 Sandy, G. N. The Greek World of Apuleius:Apuleius and the Second Sophistic, Leiden, Brill, 1997, 191-213.

7 Para los aportes apuleyanos cfr. Habermehl, P., "Quaedam divinae mediae potestates. Demonology in Apuleius' De deo Socratis", Groningen Colloquia on the Novel VII, 1996, 117-142.

8 Cfr. las explicaciones de Habermehl, "Demonology in Apuleius' De deo Socratis", 127-128.

9 Cfr. Harrison, S. J. Apuleius. A Latin Sophist, Oxford, Oxford University Press, 2000, 139.

10 El texto latino es el de la edición de Beaujeu: Apulée, Opuscules Philosophiques. Du Dieu de Socrate, Platon et sa doctrine, Du monde. Fragments. Ed. J. Beaujeu. Paris, Les Belles Lettres, 1973. Las traducciones son nuestras.

11 Sobre las fuentes, cfr. Beaujeu, Apulée, 10-14, Habermehl, “Demonology in Apuleius' De deo Socratis”, 126, y Camarero, A. Apuleyo. Tratados filosóficos. Introducción, versión española y notas de Antonio Camarero, México, Universidad Autónoma de México, 1968, XLVII-LIV.

12 Cfr. cfr. Donini, P. - Gianotti. G. F. “La luce della luna in Apuleio, De deo Socratis I, 117-119 OUD”, en Magnaldi, G. - Gianotti, G. F. Apuleio. Storia del testo e interpretazioni, Torino, Edizioni dell'Orso, 2000, 135-138.

13 Cicerón lo expresa en estos términos: [...] quinque stellarum quae falso uocantur errantes [...]

14 de Certeau, M. La invención de lo cotidiano. Vol. I: Artes de hacer, México, Universidad Iberoamericana, $2000,129$.

15 Webb, R. Ekphrasis, Imagination and Persuasion in Ancient Rhetorical Theory and Practice, England, Ashgate, 2009, 87-130.

16 Para la noción de "heterogeneidad” seguimos a Authier-Revuz, J., "Hétérogénéité(s) énonciative(s)”, Langages 73, 1984 , 98-111.

17 Sobre la relación entre discurso y naturalización ideológica, retomamos aquí las célebres consideraciones de Pêcheux, M. Semântica e Discurso. Uma Critica à Afirmaçâo do Óbvio, 1975 (trad. E. Orlandi et alii, Campinas, Unicamp, 1988).

18 Augè, M. Los no lugares. Espacios del anonimato. Una antropología de la sobremodernidad, Barcelona, Gedisa, 2005, 49-79.

19 Así, Beaujeu, Apulée, 212-215.

20 Mc Intosh, G. E. "Re-thinking the Roman Domus: How Architects and Orators construct Self, Space, and Language", Diss., The Ohio State University, 2003. 